\title{
A neuro-fuzzy model to predict the inflow to the guardialfiera multipurpose dam (Southern Italy) at medium-long time scales
}

\author{
L.F. Termite, F. Todisco, L. Vergni, F. Mannocchi \\ Department of Civil and Environmental Engineering, University of Perugia, Perugia, Italy
}

\begin{abstract}
Intelligent computing tools based on fuzzy logic and artificial neural networks have been successfully applied in various problems with superior performances. A new approach of combining these two powerful tools, known as neuro-fuzzy systems, has increasingly attracted scientists in different fields. Few studies have been undertaken to evaluate their performances in hydrologic modeling. Specifically are available rainfall-runoff modeling typically at very short time scales (hourly, daily or event for the real-time forecasting of floods) with in input precipitation and past runoff (i.e. inflow rate) and in few cases models for the prediction of the monthly inflows to a dam using the past inflows as input. This study presents an application of an Adaptive Network-based Fuzzy Inference System (ANFIS), as a neuro-fuzzy-computational technique, in the forecasting of the inflow to the Guardialfiera multipurpose dam (CB, Italy) at the weekly and monthly time scale. The latter has been performed both directly at monthly scale (monthly input data) and iterating the weekly model. Twenty-nine years of rainfall, temperature, water level in the reservoir and releases to the different uses were available. In all simulations meteorological input data were used and in some cases also the past inflows. The performance of the defined ANFIS models were established by different efficiency and correlation indices. The results at the weekly time scale can be considered good, with a NashSutcliffe efficiency index $E=0.724$ in the testing phase. At the monthly time scale, satisfactory results were obtained with the iteration of the weekly model for the prediction of the incoming volume up to 3 weeks ahead $(E=0.574)$, while the direct simulation of monthly inflows gave barely satisfactory results $(E=0.502)$. The greatest difficulties encountered in the analysis were related to the reliability of the available data. The results of this study demonstrate the promising potential of ANFIS in the forecasting of the short term inflows to a reservoir and in the simulation of different scenarios for the water resources management in the longer term.
\end{abstract}

Correspondence: Lorenzo Francesco Termite, Department of Civil and Environmental Engineering, University of Perugia, Borgo XX Giugno 74, 06121 Perugia, Italy

E-mail: lorisfrancesco.termite@studenti.unipg.it

Key words: ANFIS, streamflow forecasting, weekly time scale, model iteration.

(c) Copyright L.F. Termite et al., 2013

Licensee PAGEPress, Italy

Journal of Agricultural Engineering 2013; XLIV(s2):e158

doi:10.4081/jae.2013.s2.e158

This article is distributed under the terms of the Creative Commons Attribution Noncommercial License (by-nc 3.0) which permits any noncommercial use, distribution, and reproduction in any medium, provided the original author(s) and source are credited.

\section{Introduction}

River flow forecasting is a very important issue; in particular, when the river flows are stored in artificial reservoirs, the inflows forecasting allows to plan and adequately support the decision making for multipurpose reservoir releases both in the real time and at the inter and intra seasonal time scale. The traditional hydrological modeling techniques have been joined in recent years by alternative methods based on artificial intelligence systems, including systems based on artificial neural networks (ANNs), that bypass the problem of the parameterization of typical rainfall-runoff models and allow a significant reduction in the number of input data, while requiring long time series as input. From the combination of ANNs with fuzzy logic (Zadeh, 1965) derived neuro-fuzzy networks, which combine the main advantages of the two methodologies.

The first applications of ANNs to the problem of flow forecasting date back to the early ' 90 s (Halff et al., 1993; Hjelmfet and Wang, 1993; Karunanithi et al., 1994). In the following years ANNs or neuro-fuzzy based models have found more applications to hydrologic problems. In particular, though it is possible to find in literature applications at weekly (Zealand et al., 1999) or monthly scale (Jeong and Kim, 2005; Cannas et al., 2006; Jain and Kumar, 2007), most of the applications of such models refers to the prediction of the flow at short time scales as hourly, daily or single event time scale (Minns and Hall, 1996; Dawson and Wilby, 1998; Campolo et al., 1999; Nayak et al., 2004, 2005; Vernieuwe et al., 2005; Chen et al., 2006; Aquil et al., 2007; Firat and Gungor, 2007, 2008; Talei et al., 2010; Sarkar and Kumar, 2012). These models are useful to take timely decisions in case of extreme events, but they are not useful to plan the water resource management. On the other hand, longer time scale models have the limitation of using many input, sometimes not readily available, as for example the measured evaporation in Jeong and Kim (2005); moreover, within the same application, are sometimes used different networks for different time scales, or networks trained separately for the forecasting of low, medium and high values of the flow regime.

This study presents an application of neuro-fuzzy networks to forecast the inflows to the Guardialfiera artificial reservoir (Southern Italy). The objective is to build a single model that may be efficient in the shortmedium term (weekly scale) and that may, at the same time, enlarge the forecasting time scale trough iterations, giving indications about the inflows in the next periods in relation to possible meteorological scenarios. The implemented models use a limited number of input data, easy to find or to predict: observed values of inflows at the previous time steps and elaborations of precipitation and temperature data.

\section{Materials and methods}

The Guardialfiera Lake is a multipurpose artificial reservoir on the Biferno river (Molise Region, Southern Italy). The lake has a maxi- 
mum surface area of $7.45 \mathrm{~km}^{2}$, a gross storage capacity of $173 \mathrm{Mm}^{3}$ and a live storage capacity of $137 \mathrm{Mm}^{3}$. The catchment area is $1043 \mathrm{~km}^{2}$. The water is used for domestic, irrigation, industrial and hydropower uses.

Daily values of rainfall, minimum and maximum temperature at 12 stations upstream and 4 downstream, in the period $1974 \div 2006$, are available. Rainfall time series have a percentage of missing data lower than $6.19 \%$ in 13 stations; for 3 stations the percentage increases up to a maximum of $27.93 \%$. The percentage of missing data is more consistent for the temperature: from $48.01 \%$ to $85.63 \%$ for 9 stations, while for only 6 stations the percentage is lower than $11.41 \%$. Nevertheless, for every year data from a number of stations at least equal to 4 are available: thus, it was possible to reconstruct the missing data, using the inverse distance method (Wei and McGuinnes, 1973) for precipitation and the formulation proposed by Vergni and Todisco (2011), based on the correlation coefficient, for temperature. After the reconstruction of missing data, an estimate of the average daily temperature was obtained as the mean of the minimum and maximum daily values. Then, the time series of daily areal rainfall $R^{A}$ (Thiessen, 1911) and mean daily areal temperature $T^{A}$, relative to the upstream catchment area, were obtained after calculating the area $A_{i}$ associated to each station $i$ (Figure 1) with Thiessen's polygons method (Thiessen, 1911; Boots, 1986).

With regards to the reservoir, daily values of water level and corresponding volume for the period $1978 \div 2011$ are available. For the same period, daily values of the releases for the different uses are also available. Unfortunately, as inflows data are not available, an indirect estimate was obtained by inverting the reservoir water balance equation. However, due to error sources such as occasional incorrect readings of water level or periods of non-operation of the releases measuring instruments, there are some uncertainties in the storage and releases data, and consequently also in the estimation of the inflows. In particular, there are some more or less evident anomalies in the estimate of daily inflows, consisting mostly in very low or even negative values. Some of these outliers $(8.41 \%$ of the total data) have been corrected with a simple averaging procedure. Analyzing the time series of the flow at a gauge station located $30 \mathrm{~km}$ upstream from the reservoir, a minimum threshold for the inflow of $0.5 \mathrm{~m}^{3} / \mathrm{s}$ (corresponding to a daily inflow volume of $43200 \mathrm{~m}^{3}$ ) was identified; all values below this threshold were replaced with greater or equal values, performing media operation.

Table 1 shows a summary of climatologic data of the Biferno basin and storage volumes, inflows and outflows.

The potential of the Adaptive Network-based Fuzzy Inference (ANFIS) model (Jang, 1993) in weekly scale forecasting have been investigated and then the forecasting time horizon has been enlarged both implementing monthly scale models and iterating the best weekly model. ANFIS is the best known neuro-fuzzy model, based on ANNs and fuzzy logic.

ANNs are adaptive mathematical models constituted by a group of interconnections of informations and can be used to represent complex relationships between input and output data, that other analytical functions fail to represent. Structurally they are composed of a series of interconnected processing elements called "artificial neurons", arranged in layers. In the input layer, each neuron receives input data, in the output layer neurons provide the final result of data processing. Between these two layers there are one or more intermediate layers called "hidden layers", which have the task to process the data to arrive at the final result. In the training phase pairs of known input and corresponding output data are provided. During the training, the network modifies the parameters of the functions defined in its nodes through learning algorithms (Satyabrata and Uttam, 2013) that are iterated for a number of times said "training epochs". In this way the network acquires generalization capability, i.e. the ability to produce a plausible output starting from input data not included in the training data set.

The fuzzy logic (Zadeh, 1965) is based on the concept of fuzzy sets, defined as sets with no crisp boundaries; unlike the two-valued Boolean logic, fuzzy logic uses any real value between 0 (completely false) and 1 (completely true), which is known as membership value; the function representing such values is called membership function. On this basis, inferential systems such as the Takagi-Sugeno one (Takagi and Sugeno, 1985) are built.

The ANFIS model acquires knowledge from data using typical ANNs' algorithms, but represent it using fuzzy rules.

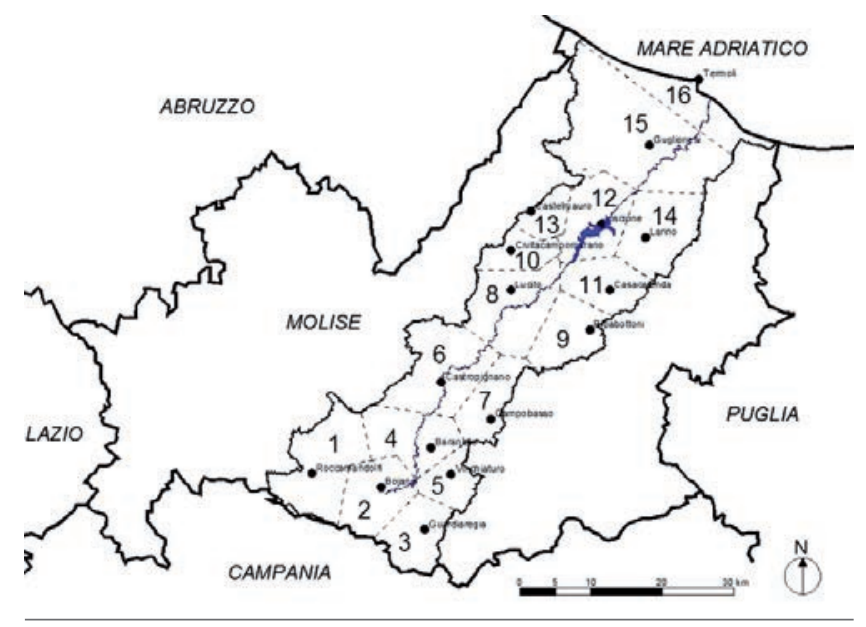

Figure 1. Basin of the Biferno river within Molise region and division in Thiessen polygons .
Table 1. Principal characteristics of Biferno basin climate regime and Guardialfiera Lake storage, inflow and outflow volumes .

\begin{tabular}{lccc} 
& Minimum & Maximum & Mean \\
Annual $\mathrm{R}^{\mathrm{A}}(\mathrm{mm})$ & 635.3 & 1242.0 & 942.2 \\
Mean $\mathrm{T}_{\text {min }}^{\mathrm{A}}\left({ }^{\circ} \mathrm{C}\right)$ & 7.4 & 10.3 & 8.9 \\
\hline Mean $\mathrm{T}_{\text {max }}^{\mathrm{A}}\left({ }^{\circ} \mathrm{C}\right)$ & 16.2 & 19.7 & 18.0 \\
Mean $\mathrm{T}_{\text {mean }}^{\mathrm{A}}\left({ }^{\circ} \mathrm{C}\right)$ & 11.8 & 14.8 & 13.4 \\
\hline $\mathrm{V}_{\text {min }}\left(\mathrm{Mm}^{3}\right)$ & 22.89 & 110.11 & 78.74 \\
$\mathrm{~V}_{\text {max }}\left(\mathrm{Mm}^{3}\right)$ & 50.50 & 154.94 & 129.21 \\
\hline Mean $\mathrm{I}\left(\mathrm{Mm}^{3}\right)$ & 0.35 & 1.71 & 0.84 \\
Mean $\mathrm{O}_{1}\left(\mathrm{Mm}^{3}\right)$ & 0.09 & 1.52 & 0.55 \\
\hline Mean $\mathrm{O}_{2}\left(\mathrm{Mm}^{3}\right)$ & 0.02 & 0.04 & 0.02 \\
Mean $\mathrm{O}_{3}\left(\mathrm{Mm}^{3}\right)$ & 0.01 & 0.56 & 0.22 \\
\hline Mean $\mathrm{O}_{4}\left(\mathrm{Mm}^{3}\right)$ & 0.00 & 0.08 & 0.03
\end{tabular}

Annual $\mathrm{R}^{\mathrm{A}}$ : annual areal rainfall (1974-2006); Mean $\mathrm{T}_{\mathrm{min}}^{\mathrm{A}}$ : mean of the minimum daily areal temperature (1974-2006); Mean $\mathrm{T}_{\text {max }}^{\mathrm{A}}$ : mean of the maximum daily areal temperature (1974-2006); Mean TA $\mathrm{m}_{\text {mean }}$ : mean of the mean daily areal temperature (1974-2006); $\mathrm{V}_{\min }$ annual minimum storage volume (1978-2011); $V_{\text {max: }}$ annual maximum storage volume (1978-2011); mean I: mean daily inflow volume (1978-2011); mean $\mathrm{O}_{1}$ : mean daily bed release volume (1978-2011); mean $\mathrm{O}_{2}$ : mean daily release volume for civil use (19852011); mean $\mathrm{O}_{3}$ : mean daily release volume for industrial and agricultural use (1978-2011); mean $\mathrm{O}_{4}$ : mean daily release volume for hydroelectric use (1999-2011). 
In order to select the input data among the various elaborations of available data, analyses of correlation between inflows and meteorological data were carried out. Different ANFIS models for inflows simulation were then implemented, varying the input/output combinations (Table 2) and the network's structure. Given the different periods covered by the meteorological data $(1974 \div 2006)$ and those relating to the management of the reservoir $(1978 \div 2011)$, it was possible to use only the common period data $(1978 \div 2006)$, with a total of 10592 values of daily inflows and a number of input/output vectors varying from 10542 to 10592 depending on timely data aggregation. In all simulations, data from 1978 to 1996 and from 2002 to 2006 (number of vectors varying from 8716 to 8766) were used as training data, while those from 1997 to 2001 (1826 vectors) were selected as testing data. This choice is justified by the fact that the period $1997 \div 2001$ is characterized by a fairly standardized inflows trend, while up to 1992 and from 2003 onwards there are inflow peaks that is worthwhile to insert in the training data.

The implemented models were evaluated with: a) standard regression indices, as the slope and the intercept of the observed vs. simulated data linear regression line; Pearson's correlation coefficient $r$ and the coefficient of determination $R^{2}$; b) adimensional efficiency indices, as the efficiency index $E$ (Nash and Sutcliffe, 1970); the modified efficiency index $E_{1}$ (Legates and McCabe, 1999); the index of agreement $d$ (Willmott, 1981) and the modified index of agreement $d_{1}$ (Wilmott et al. 1985); c) error indices, as the Root Mean Square Error RMSE; the Mean Absolute Error MAE; the Mean Absolute Percentage Error MAPE; the percent-bias index PBIAS (Gupta et al., 1999) and the RMSE-observation Standard deviation Ratio RSR (Singh et al., 2004).

Particular attention is given to $E, P B I A S$ and $R S R$ values, that have been compared with the ranges identified by Moriasi et al. (2007) in their guidelines for the evaluation of hydrological simulation models.

\section{Results and discussion}

The weekly time scale model that gave the best results, called Liscione_67, has the input/output combination n. 6 in Table 2. The model was built with 4 triangular membership functions for each input and constant function for the output; it was trained for 200 epochs with the hybrid learning algorithm.

The use of input as meteorological data relative to the same period of the forecasted inflows obviously introduces new variables when these models are actually applied. However, today's weather prediction models allow to have a fairly good estimate of rainfall within the next 6 days (Chou et al., 2000; Collischonn et al., 2007). Graphical results on the testing data are presented in Figures 2 and 3. Table 3 shows the results in term of statistical indices for both training and testing data. The results on the training data can be defined "very good" for all $E, P B I A S$ and $R S R$ indices according to the classification proposed by Moriasi et al. (2007). In particular, the PBIAS index shows the optimal value 0.000 . With regards to the testing data, the value of $E$ equal to 0.724 and $R S R$ equal to 0.525 allow to classify the model as "good"; the PBIAS value -20.151 instead fall within the range of "satisfactory" values and reveals the general tendency of the model to overestimate the inflows.

Anyway, the guidelines proposed by Moriasi et al. (2007) refer to simulations at monthly scale, while the Liscione_ 67 model uses a weekly scale. According to the authors, less restrictive evaluation criteria can be adopted in case of time scales shorter than monthly, and also in the case of considerable uncertainties on the data used for the simulation and when the objective of the study is to investigate the technology potential and to perform a base research: all these conditions fall in this study, so the results can be considered very satisfactory.

Table 2. Input and output data of the implemented models.

\begin{tabular}{|c|c|c|c|}
\hline Combination number & Input & Target/output & $\begin{array}{c}\text { Number of } \\
\text { input/output vectors }\end{array}$ \\
\hline 1 & $R^{A}(t \div t+6), T_{\text {mean }}^{A}(t \div t+6)$ & $I(t \div t+6)$ & 10591 \\
\hline 2 & $\mathrm{R}^{\mathrm{A}}(\mathrm{t}-1 \div \mathrm{t}+5), \mathrm{T}_{\text {mean }}^{\mathrm{A}}(\mathrm{t}-1 \div \mathrm{t}+5)$ & $I(t \div \mathrm{t}+6)$ & 10587 \\
\hline 3 & $R A(t-1 \div t+5), I(t-7 \div t-1)$ & $\mathrm{I}(\mathrm{t} \div \mathrm{t}+6)$ & 10580 \\
\hline 4 & $\mathrm{R}^{\mathrm{A}}(\mathrm{t}-1 \div \mathrm{t}+5), \mathrm{T}_{\text {mean }}^{\mathrm{A}}(\mathrm{t}-1 \div \mathrm{t}+5), \mathrm{I}(\mathrm{t}-7 \div \mathrm{t}-1)$ & $\mathrm{I}(\mathrm{t} \div \mathrm{t}+6)$ & 10580 \\
\hline 5 & $\mathrm{R}^{\mathrm{A}}(\mathrm{t}-7 \div \mathrm{t}-1), \mathrm{T}_{\text {mean }}^{\mathrm{A}}(\mathrm{t}-7 \div \mathrm{t}-1), \mathrm{I}(\mathrm{t}-7 \div \mathrm{t}-1)$ & $\mathrm{I}(\mathrm{t} \div \mathrm{t}+6)$ & 10585 \\
\hline 6 & $R^{A}(t \div t+6), T_{\text {mean }}^{A}(t \div t+6), I(t-7 \div t-1)$ & $\mathrm{I}(\mathrm{t} \div \mathrm{t}+6)$ & 10579 \\
\hline 7 & $\mathrm{I}(\mathrm{t}-7 \div \mathrm{t}-1), \mathrm{I}_{\mathrm{stat}}(\mathrm{t} \div \mathrm{t}+6)$ & $I(t \div \mathrm{t}+6)$ & 10585 \\
\hline 8 & $\mathrm{R}^{\mathrm{A}}(\mathrm{t}-7 \div \mathrm{t}-1), \mathrm{R}_{\text {stat }}^{\mathrm{A}}(\mathrm{t} \div \mathrm{t}+6), \mathrm{T}_{\text {mean }}^{\mathrm{A}}(\mathrm{t}-7 \div \mathrm{t}-1), \mathrm{T}_{\text {mean, stat }}^{\mathrm{A}}(\mathrm{t} \div \mathrm{t}+6), \mathrm{I}(\mathrm{t}-7 \div \mathrm{t}-1)$ & $\mathrm{I}(\mathrm{t} \div \mathrm{t}+6)$ & 10585 \\
\hline 9 & $\mathrm{I}(\mathrm{t}-7 \div \mathrm{t}-1), \mathrm{I}_{\text {stat }}(\mathrm{t}-7 \div \mathrm{t}-1), \mathrm{I}_{\text {stat }}(\mathrm{t} \div \mathrm{t}+6)$ & $I(t \div \mathrm{t}+6)$ & 10585 \\
\hline 10 & $\mathrm{R}_{\text {stat }}(\mathrm{t} \div \mathrm{t}+6), \mathrm{T}_{\text {mean, stat }}(\mathrm{t} \div \mathrm{t}+6), \mathrm{I}(\mathrm{t}-7 \div \mathrm{t}-1)$ & $\mathrm{I}(\mathrm{t} \div \mathrm{t}+6)$ & 10585 \\
\hline 11 & $R^{A}(t \div t+6), R_{\text {stat }}^{A}(t \div t+6), T_{\text {mean }}^{A}(t \div t+6), T_{\text {mean,stat }}^{A}(t \div t+6), I_{\text {stat }}(t \div \mathrm{t}+6)$ & $I(t \div \mathrm{t}+6)$ & 10586 \\
\hline 12 & $\mathrm{R}^{\mathrm{A}}(\mathrm{t}-90 \div \mathrm{t}-1), \mathrm{T}_{\text {mean }}^{\mathrm{A}}(\mathrm{t}-15 \div \mathrm{t}-1)$ & $\mathrm{I}(\mathrm{t} \div \mathrm{t}+29)$ & 10592 \\
\hline 13 & $\mathrm{R}^{\mathrm{A}}(\mathrm{t}-90 \div \mathrm{t}-1), \mathrm{T}_{\text {mean }}^{\mathrm{A}}(\mathrm{t}-15 \div \mathrm{t}-1), \mathrm{I}(\mathrm{t}-30 \div \mathrm{t}-1)$ & $I(t \div t+29)$ & 10562 \\
\hline 14 & $\mathrm{R}^{\mathrm{A}}(\mathrm{t}-9 \div \mathrm{t}+20), \mathrm{T}_{\text {mean }}(\mathrm{t}-9 \div \mathrm{t}+20), \mathrm{I}(\mathrm{t}-30 \div \mathrm{t}-1)$ & $\mathrm{I}(\mathrm{t} \div \mathrm{t}+29)$ & 10542 \\
\hline 15 & $\mathrm{R}^{\mathrm{A}}(\mathrm{t}-9 \div \mathrm{t}+20), \mathrm{T}_{\text {mean }}^{\mathrm{A}}(\mathrm{t}-9 \div \mathrm{t}+20)$ & $I(t \div t+29)$ & 10572 \\
\hline 16 & $R^{A}(t-9 \div t+20), I(t-30 \div t-1)$ & $I(t \div t+29)$ & 10542 \\
\hline
\end{tabular}


Nevertheless, analyses were carried to understand the principal causes of error.

The analysis of the absolute frequencies of observed and simulated values showed a tendency to overestimate lower values, as shown also in Figure 3. Moreover, the analysis of the absolute frequencies of the differences between observed and simulated values confirms a general model's tendency to overestimate, already indicated by the negative value of the PBIAS index. It was also verified that, with respect to the testing data, in $6 \%$ of cases the absolute difference between the observed and simulated value is greater than $5 \mathrm{Mm}^{3}$; these cases (white dots in Figure 3 ) greatly influence the efficiency index $E$ and are mainly due to overestimation of the lower values and underestimation of the higher ones. It was also analyzed the cumulative frequency of the data used as input, both for all testing data and only for those cases in which the absolute difference between observed and simulated data exceeds $5 \mathrm{Mm}^{3}$. It was thus possible to observe that the largest errors occur when precipitation values are higher than the average ones, when temperature values are lower than the average ones and in correspondence of high differences between the inflows of consecutive weeks (percentage difference higher than 100\%). This analysis suggests that in order to reduce the prediction error it is reasoning to focus the attention on some particular periods of the year, especially autumn and winter. Beyond these considerations, an interesting result was obtained by analyzing the dates with absolute differences greater than $5 \mathrm{Mm}^{3}$. The analysis showed that they are grouped into 14 periods of few consecutive days; most of these periods are characterized by initial uncertainties on the values of the inflows and in many cases the inflow values have been reconstructed as described previously. It is therefore reasonable to think that these uncertainties had a decisive weight in the model performance. In order to verify the weight of the initial uncertainties, it was constructed, trained and tested a new model, called Liscione_67_b, obtained removing from both the training and the testing set all the input/output vectors that contain reconstructed values of the inflows. Because of the weekly aggregation of the inflows in both the input and output data, this led to a reduction of the input/output vectors of $31.4 \%$ in the training set and of $55.3 \%$ in the testing set. The simulation results on the training and testing data, reported in Table 3, show an improvement over Liscione_67 in terms of the statistical indices. With regard to the testing data, the efficiency index $E$ increases from 0.724 to 0.761 and $R S R$ decreases from 0.525 to 0.489 . The model performance rating on both these indices, according to Moriasi et al. (2007), changes from "good" to "very good." The value of PBIAS improves too, decreasing from -20.151 to -17.891, however the performance rating on this index remains "satisfactory".

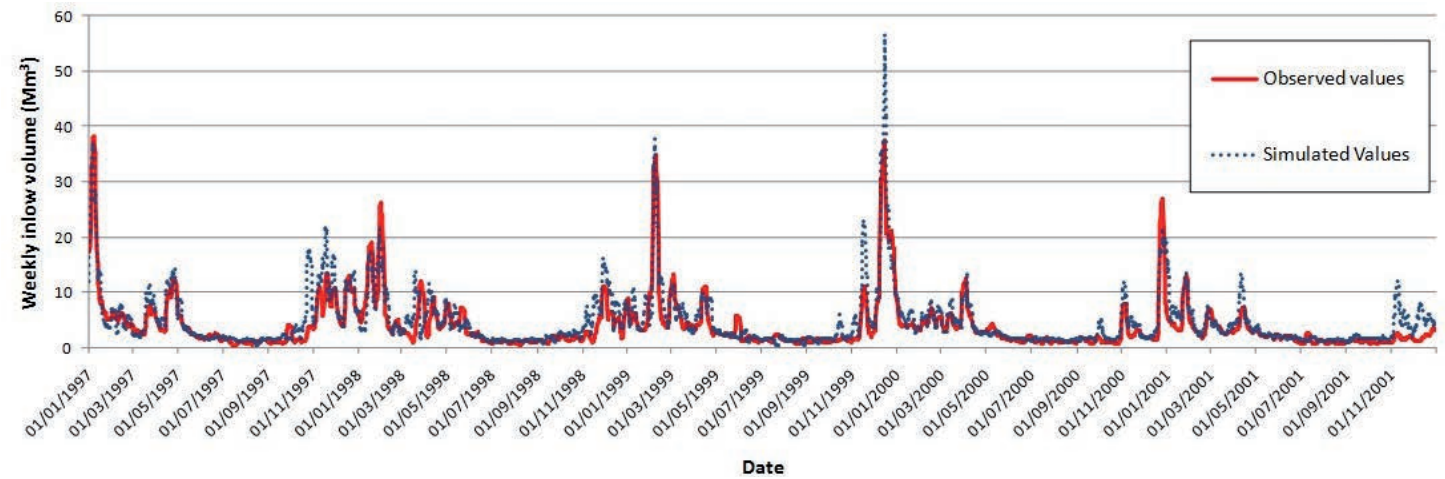

Figure 2. Observed and simulated weekly inflow volumes in the testing period (1997-2001) for Liscione_67 Model.

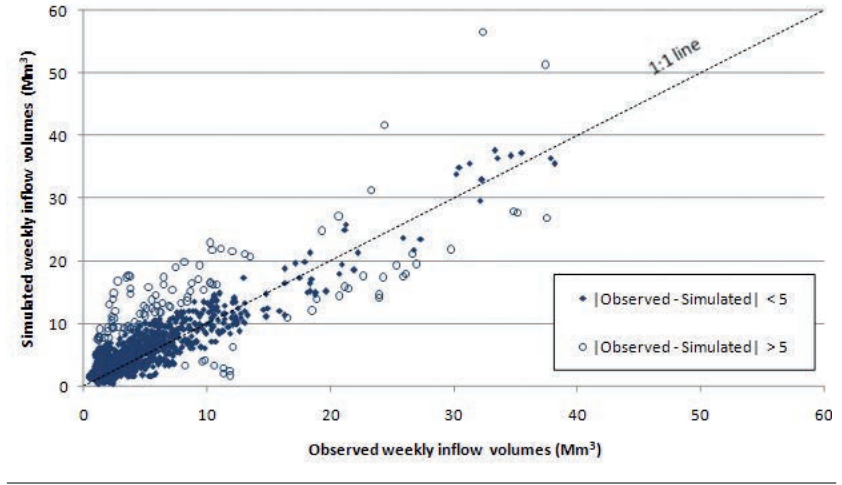

Figure 3. Observed vs simulated weekly inflow volumes in the testing period (1997-2001) for Liscione_67 Model.
Table 3. Results of the weekly time scale models Liscione_67 and Liscione_67_b.

\begin{tabular}{lcccc}
\multicolumn{5}{c}{ Liscione_67 Modelliscione_67_b Model } \\
\\
Slope & Training data & Testing data & Training data & Testing data \\
Intercept & 0.797 & 0.946 & 0.812 & 0.951 \\
\hline $\mathrm{r}$ & $1.28 \mathrm{E}+06$ & $1.02 \mathrm{E}+06$ & $1.44 \mathrm{E}+06$ & $1.36 \mathrm{E}+06$ \\
\hline R2 & 0.893 & 0.886 & 0.901 & 0.904 \\
\hline E & 0.797 & 0.785 & 0.812 & 0.817 \\
E1 & 0.797 & 0.724 & 0.812 & 0.761 \\
\hline d & 0.633 & 0.486 & 0.643 & 0.478 \\
d1 & 0.940 & 0.933 & 0.946 & 0.942 \\
\hline RMSE & 0.809 & 0.751 & 0.815 & 0.740 \\
MAE & $3.87 \mathrm{E}+06$ & $2.57 \mathrm{E}+06$ & $4.07 \mathrm{E}+06$ & $2.86 \mathrm{E}+06$ \\
\hline MAPE & $1.97 \mathrm{E}+06$ & $1.53 \mathrm{E}+06$ & $2.15 \mathrm{E}+06$ & $1.90 \mathrm{E}+06$ \\
PBIAS & 39.92 & 54.07 & 31.75 & 43.66 \\
\hline & 0.000 & -20.151 & 0.000 & -17.891 \\
\hline
\end{tabular}


The monthly scale model that gave the best results has the input/output combination n. 16 in Table 2, with total precipitation from day $t-9$ to day $t+20$ and observed inflows from $t-30$ to $t-1$ as inputs. Typically, when ANNs are used for the simulation of flows at monthly scale, the input data used are the flow values at previous time steps (Atiya et al., 1999; Cannas et al., 2006; Jain and Kumar, 2007). In fact, it is difficult to relate the upcoming month flow value with past meteorological data, especially in small basins in which the rainfall-runoff process is exhausted in a short time. Indeed, the results obtained using these kind of input have not proved satisfactory. On the other hand, the use of future values of rainfall as input data involves uncertainties related to the their prediction beyond a certain time horizon, although in literature there are examples of meteorological modeling that produce accurate predictions even at a monthly or seasonal time scale (Chou et al. 2000; Chou et al. 2005). The model was built with 4 triangular membership functions for each input and constant function for the output, and trained for 200 epochs with the hybrid learning algorithm. Good results on the training data contrast with poorer results on the testing data, with a barely satisfactory efficiency index $E=0.502$.

Another possible way to enlarge the forecasting time scale is the iteration of the same model (Atiya et al., 1999), when among the input data there is the same variable produced as output (for example, when the upcoming flow value is simulated using the flow values at previous time steps as input). The Liscione_67 model was thus iterated, using the output inflow value as input for the next step. The output values from all the simulation steps were then added together and compared with the total inflow values in the corresponding days. The performance get worse at every iteration, due to the casual propagation of errors; in particular, satisfactory results were obtained up to the second iteration, with an efficiency index $E=0.574$ relative to the forecast of the inflow volumes up to 20 days ahead.

\section{Conclusions}

ANFIS models for the forecasting of the inflow volumes to the Guardialfiera dam at the weekly and monthly time scale were implemented in this study. These models allow to use a smaller number of input data compared to the traditional hydrologic modeling and make it possible to simulate the flow regimes even from just a few and readily available data such as meteorological ones; in particular, in this study daily data of rainfall, temperature and storage volume in the period $1978 \div 2006$ were used.

The results at the weekly scale have proved good, with an efficiency index $E=0.724$ on the testing data. The model tends to overestimate the inflows, especially the lower values. At the monthly scale the results are poorer, because it's more difficult to relate monthly values of the inflows with rainfall and temperature data. The best result of the direct simulation of the monthly inflows gave an efficiency index $E=0.502$. Moreover, iterations of the best performing weekly model were performed, thus obtaining forecasts of the cumulated values of inflows in the upcoming weeks. In this case there is a casual error propagation at every iteration and the model performance get worse compared to the first step. In particular, satisfactory results were obtained up to the second iteration, with an efficiency index $E=0.574$, thus obtaining satisfactory forecasts of the inflow volumes up to 20 days ahead.

The principal causes of error were investigated and it was found that these type of models are very sensitive to input data that differ much from their mean values. Moreover, especially when the number of input data is small, it is necessary that the input time series are accurate and without uncertainties, since the latter strongly influence the performance of the models, as demonstrated in this work. Data preprocessing, aimed to reduce the weight of the outliers, is thus useful. In addition, it is appropriate to ensemble a training set including all possible cases or, however, the extreme cases, in terms of both minimum and maximum, among the available data. In this study, the division into training and testing set was made a priori, including all the extreme values of the inflows in the training set and choosing a testing set characterized by rather standardized values of the inflow volumes. However, it could be interesting to check the model performance varying the training and testing sets with a cross-validation technique.

The best performing models use future values of rainfall and temperature as inputs, that obviously would not be known a priori in case of their actual application. However, today it is possible to obtain very accurate estimations of rainfall and temperature values in the upcoming week and even at longer term.

In conclusion, with the implemented ANFIS model it is possible to forecast fairly accurately the inflow volumes in the short term, while for longer periods it is possible to simulate different scenarios, varying predictions on meteorological data, and formulate hypotheses of water resource management.

\section{References}

Aqil M., Kita I., Yano A., Nishiyama S. 2007. A comparative study of artificial neural networks and neuro-fuzzy in continuous modeling of the daily and hourly behaviour of runoff. J. Hydrol. 337:22-34.

Atiya A. F., El-Shoura S. M., Shaheen S. I., El-Sherif M. S. 1999. A comparison between neural-network forecasting techniques - Case study: river flow forecasting. IEEE T. Neural Networ. 10:402-9.

Boots B. N. 1986. Voronoi (Thiessen) Polygons. Concepts and Techniques in Modern Geography 45, Geo Book, Norwich.

Campolo M., Andreussi P., Soldati A. 1999. River flow forecasting with a neural network model. Water Resour. Res. 35:1191-97.

Cannas B., Fanni A., See L., Sias G. 2006. Data preprocessing for river flow forecasting using neural networks: Wavelet transforms and data partitioning. Phys. Chem. Earth 31:1164-71.

Chen S.-H., Lin Y.-H., Chang L.-C., Chang,F.-J. 2006. The strategy of building a flood forecast model by neuro-fuzzy network. Hydrol.Process. 20:1525-40.

Chou S. C., Nunes A. M. B., Cavalcanti I. F. A. 2000. Extended range forecasts over South America using the regional Eta model. J. Geophys. Res. 105:10147-60.

Chou S. C., Bustamante J. F., Gomes J, L. 2005. Evaluation of Eta model seasonal precipitation forecasts over South America. Nonlinear Proc. Geoph. 12:537-55.

Collischonn W., Morelli Tucci C. E., Clarke R. T., Chou S. C., Guilhon L. G., Cataldi M., Allasia D. 2007. Medium-range reservoir inflow predictions based on quantitative precipitation forecasts. J. Hydrol. 344:112-22.

Dawson C. W., Wilby R. 1998. An artificial neural network approach to rainfall-runoff modelling. Hydrolog. Sci. J. 43:47-66.

Firat M., Gungor M. 2007. River flow estimation using adaptive neuro fuzzy inference system. Math. Comput. Simulat. 75:87-96.

Firat, M., Gungor M. 2008. Hydrological time-series modeling using an adaptive neuro-fuzzy inference system. Hydrolo. Process. 22:212232.

Gupta H. V., Sorooshian S., Yapo P. 0. 1999. Status of automatic calibration for hydrologic models: comparison with multilevel expert calibration. J. Hydrol. Eng. 4:135-43.

Halff A. H., Halff H. M., Azmoodeh M. 1993. Predicting runoff from rainfall using neural networks. Proc. Engng. Hydrol., ASCE, New York, $760-5$. 
Hjelmfelt A. T., Wang M. 1993. Artificial neural networks as unit hydrograph applications. Proc. Engng. Hydrol., ASCE, New York, 1993, 754-9.

Jain A., Kumar A. M. 2007. Hybrid neural network models for hydrologic time series forecasting. Appl. Soft Comput. 7:585-92.

Jang J.-S. R. 1993. ANFIS: Adaptive-Network-Based Fuzzy Inference System. IEEE T. Syst. Man Cyb. 23:665-85.

Jeong D.-I., Kim, Y.-0. 2005. Rainfall-runoff models using artificial neural networks for ensemble streamflow prediction. Hydrol. Process. 19:3819-35.

Karunanithi N., Grenney W. J., Whitley D., Bovee K. 1994. Neural networks for river flow prediction. J.Comput. Civil Eng. 2:203-19.

Legates D. R., McCabe G. J. 1999. Evaluating the use of "goodness-offit" measures in hydrologic and hydroclimatic model validation. Water Resour. Res. 35:233-41.

Minns A. W., Hall M. J. 1996. Artificial neural networks as rainfallrunoff models. Hydrolog. Sci. J. 41:399-418.

Moriasi D. N., Arnold J. G., Van Liew M. W., Bingner R. L., Harmel R. D., Veith T. L. 2007. Model evaluation guidelines for systematic quantification of accuracy in watershed simulations. T. ASABE 50:885900.

Nash J. E., Sutcliffe J. V. 1970. River flow forecasting through conceptual models: Part 1. A discussion of principles. J. Hydrol. 10:282-90.

Nayak P. C., Sudheer K. P., Rangan D. M., Ramasastri K. S. 2004. A neuro-fuzzy computing technique for modeling hydrological time series. J. Hydrol. 291:52-66.

Nayak P. C., Sudheer K. P., Rangan D. M., Ramasastri K. S. 2005. Shortterm flood forecasting with a neurofuzzy model. Water Resour. Res. 41, article W04004.

Sarkar A., Kumar R. 2012. Artificial neural networks for event based rainfall-runoff modeling. J. Water Resour. Prot. 4:891-897.
Satyabrata P., Uttam R. 2013. ANFIS based weld metal deposition prediction system in mag welding using hybrid learning algorithm. Int. J. Fuzzy Log. Syst. 3:33-46.

Singh J., Knapp H. V., Demissie M. 2004. Hydrologic modeling of the Iroquois river watershed using HSPF and SWAT. ISWS CR 2004-08. Champaign, Ill.: Illinois State Water Survey.

Takagi T., Sugeno M. 1985. Fuzzy identification of systems and its applications to modeling and control. IEEE T. Syst. Man Cyb. 15:116-32.

Talei A., Chua L. H. C., Quek C. 2010. A novel application of a neurofuzzy computational technique in event-based rainfall-runoff modeling. Expert Syst. Appl. 37:7456-68.

Thiessen A. H. 1911. Precipitation averages for large areas. Mon. Weather Rev. 39:1082-4.

Vergni L., Todisco F. 2011. Spatio-temporal variability of precipitation, temperature and agricultural drought indices in Central Italy. Agr. Forest Meteorol. 151:301-13.

Vernieuwe H., Georgieva 0., De Baets B., Pauwels V. R. N., Verhoest N. E. C., De Troch F. P. 2005. Comparison of data-driven TakagiSugeno models of rainfall-discharge dynamics. J. Hydrol. 302:17386.

Wei T. C., McGuinnes J. L. 1973. Reciprocal distance squared method, a computer technique for estimating area precipitation. Technical Report ARS-Nc-8. US Agricultural Research Service, North Central Region, Ohio.

Willmott C. J. 1981. On the validation of models. Phys. Geogr. 2:184-94.

Willmott C. J., Ackleson S. G., Davis R. E., Feddema,J. J., Klink K. M., Legates D. R., O'Donnell J., Rowe C. M. 1985. Statistics for the evaluation and comparison of models. J. Geophys. Res.90:8995-9005.

Zadeh L. A. 1965. Fuzzy sets. Inform. Control 8:338-53.

Zealand C. M., Burn D. H., Simonovic,S. P. 1999. Short term streamflow forecasting using artificial neural networks. J. Hydrol. 214:32-48. 